\title{
Comment \\ Enological Repercussions of Non-Saccharomyces Species
}

\author{
Agustín Aranda \\ Institute for Integrative Systems Biology, I²SysBio, University of Valencia-CSIC, 46980 Paterna, Spain; \\ agustin.aranda@csic.es
}

Received: 13 July 2019; Accepted: 18 July 2019; Published: 24 July 2019

The bulk of the sugar fermentation in grape juice, in order to produce wine is carried out by yeasts of the genus Saccharomyces, mainly S. cerevisiae. However, S. cerevisiae is not the only wine yeast, as spontaneous grape juice fermentation involves a complex succession of growth and death of different yeasts [1,2], and each of them contribute to the organoleptic properties of the final product. Saccharomyces are not usually found in the epiphytic yeasts present on the surface of grapes, where Hanseniaspora, Candida, Pichia, and Hansenula are dominant [3]. However, Saccharomyces imposes itself due to its higher tolerance to the stressful conditions of fermentation, due to its resistance to the addition of sulfite and to the ethanol that it itself produces [4]. Therefore, most non-Saccharomyces species relevant to winemaking have been traditionally overlooked, except when they act as spoilage agents [5]. However, the use of selected non-conventional yeasts to improve the organoleptic properties of wine is probably the most exciting trend in modern enological microbiology [6-8]. This Special Issue gives a complete picture of the most promising non-Saccharomyces strains and their contributions towards more complex and balanced wines.

Spoilage yeasts are still the subject of much interest. One of the most resilient contaminants in the cellar are Brettanomyces/Dekkera yeasts. B. bruxellensis has been described as being mainly responsible for worldwide off-flavor wine production, due to its ability to transform hydroxycinnamic acids present in the grape juice into phenolic derivatives [9]. Brettamomyces has been controlled traditionally by the addition of sulfur dioxide, but the current trend is to reduce the use of such chemical agents due to its negative impact on human health. Therefore, alternatives are being explored. The use of killer toxins produced by different non-Saccharomyces yeasts have been described, and the most promising one is the use of antimicrobial peptides. Interestingly, a peptide derived from a strain of Candida intermedia isolated form wine fermentations proved useful against B. bruxellensis, which leads to the possibility of this and other yeasts to be used as agents for biological control. Zygosaccharomyces is also a well-known wine spoilage yeast, causing re-fermentation in sweet wines and producing not just $\mathrm{CO}_{2}$ but also undesired compounds such as some esters [10]. However, Z. rouxii has been used to produce low-alcohol beer, and co-cultivation of. S. cerevisiae and Z. bailii produces wine with lower ethanol content. High stress tolerance and low oxygen requirements would make this genus fit to produce sparkling wines, but its production of off-flavors, such as acetoin, might be detrimental. Another spoilage yeast with a high stress tolerance is Saccharomycodes ludwigii [11]. Due to its high tolerance to sulfur dioxide it can become a serious problem in the winery. However, it has some positive abilities, like reducing the alcoholic content in mixed fermentations, the high release of polysaccharides in wine (during aging-on-lees, as a result of cellular autolysis, but also during growth and alcoholic fermentation) and the aromatic profile improvement of mixed fermentations.

Fission yeast Schizosaccharomyces pombe is one of the non-conventional yeasts that has raised more early interest [12]. S. pombe is naturally found in grape juice and has the ability to reduce the L-malic in wine, through maloalcoholic fermentation into ethanol and $\mathrm{CO}_{2}$. That is a way to control the acidity of wines, producing more balanced products when acidity is high. However, due to its slow growth and 
the fact that it produces wines with a less fruity tone, its use as unique fermenting yeasts is ruled out. However, the use of immobilized $S$. pombe has proved to be an alternative to reduce malic acid in a controlled way. Additionally, this yeast helps to stabilize color and to release polysaccharides during ageing on lees. Torulaspora delbrueckii is probably the most suitable of non-Saccharomyces yeasts for use in winemaking [13]. It has a better fermentative performance that any of the other non-conventional yeasts mentioned here, and it has some positive aspects that might improve wine fermentation when compared to $S$. cerevisiae-low acetic acid and ethanol production, high glycerol production and mannoprotein and polysaccharide release-along with some interesting contributions to the final aroma. However, it is more sensitive to stress than S. cerevisiae, it dies faster, and also its metabolic activity declines markedly as a result of the environmental stress.

The genus of apiculate yeast Hanseniaspora and its asexual anamorph Kloeckera is the most abundant yeast associated with grapes. Its tolerance to ethanol and sulfite is low, so their contribution during a spontaneous fermentation is restricted to the first stages [14]. However, its contribution to the organoleptic properties of the final product produced by S. cerevisiae is remarkable. Some specific species that are relatively well-adapted to wine fermentation have attracted interest. For instance, strains of $H$. vineae has been demonstrated to increase fruity aromas by increasing 2-phenylethyl acetate and ethyl acetate. All Hanseniaspora species increase the level of almost all acetate esters. Some species, such $H$. clermontiae, $H$. opuntiae, $H$. guilliermondii, and $H$. vineae are also able to stabilize the color of wines. Other genera that are easily found in grapes and wineries are Candida. Some strains of C. stellata have been associated with food production for a long time [15]. It has a positive impact in winemaking for its fructophilic character, its high glycerol production, and its efficient production of extracellular enzymes, such as pectinases, cellulases, proteases, glycosidases, and so on. Candida is a complex genus from the genetic point of view, and for instance a C. stellata strain of enological interest has been renamed Starmerella bombicola, while other food related species C. zemplinina has been renamed Starmerella bacillaris, so this variety of yeasts with interesting industrial properties have to be carefully studied. A similar change of name has suffered Wickerhamomyces anomalus, which was previously known as Pichia anomala, Hansenula anomala or Candida pelliculosa [16]. This yeast is present in grape juice fermentations, and while it was traditionally associated with a high ethyl acetate production it has been proved to be a good enzyme producer. For instance, it produces high amounts of glycosidases that contribute to the release of primary aromas from the grape. It also produces a high level of proteases that prevent wine haze.

Most non-Saccharomyces yeasts change the wine properties with a variety of small changes in the final product, while others have a very distinct advantage. The main advantage of Lachancea thermotolerans (previously known as Kluyveromyces thermotolerans) is its strong production of lactic acid, a fact that can lower the wine $\mathrm{pH}$ by 0.5 units or even more [17]. This prevents the addition of tartaric acid in cases where the acidity is sub-optimal. Additionally, it helps to reduce the volatile acidity when mixed with S. cerevisiae. Metschnikowia (Candida) pulcherrima can be used as a biological control agent due to its production of a natural antimicrobial compound, pulcherrimin, which has antifungal properties [18]. It also helps stabilize the wine's color due to its low anthocyanin absorption rates and the formation of stable pigments (pyranoanthocyanins and polymers). The saprophytic yeast-like fungus Aureobasidium pullulans shows antagonistic activity against plant pathogens and it has the ability to decrease ochratoxin A (OTA) production and OTA biosynthetic gene expression of the contaminating fungus [19].

Due to their lower fermentative potential, compared to $S$. cerevisiae, the non-Saccharomyces species are used in mixed or sequential fermentation with an $S$. cerevisiae strain with good fermentative power to achieve the complete consumption of sugars from grape juice. Non-conventional yeasts might help to improve the most undesired aspect of a given fermentation. With regards to wine acidity, up to seven non-Saccharomyces species can increase or decrease acidity [20]. By doing so they can be useful to prevent the unbalances produced through the increasing levels of global warming. Finally, non-Saccharomyces yeasts can be useful in the production of wines involving specific post-fermentation 
processes, such as the case of sparkling wine [21]. Secondary fermentation can be carried out by T. delbrueckii giving positive effects on the overall aroma and sensory characteristics. Presence of S. pombe and Saccharomycodes ludwigii influence the acidity and color of the final product, and of course, the presence of non-Saccharomyces in the primary fermentation has its fingerprint in the sensory quality of sparkling wines. For all these reasons there is an increasingly longer list of non-Saccharomyces species used as commercial starters, particularly of T. delbrueckii, where five distinct commercial brands are now available.

Funding: This work has been funded by a grant from the Spanish Ministry of Economy and Competiveness (AGL2017-83254-R).

Conflicts of Interest: The authors declare no conflict of interest.

\section{References}

1. Fleet, G.H. The microorganisms of wine making. In Wine Microbiology and Biotechnology; CRC Press: Boca Raton, FL, USA, 1993; pp. 1-27.

2. Ribéreau-Gayon, P.; Dubourdieu, D.; Donèche, B. Handbook of Enology, 2nd ed.; John Wiley: Chichester, UK; Hoboken, NJ, USA, 2006.

3. Jackson, R.S. Wine Science: Principles, Practice, Perception, 2nd ed.; Academic Press: San Diego, Spain, 2000; p. 648.

4. Matallana, E.; Aranda, A. Biotechnological impact of stress response on wine yeast. Lett. Appl. Microbiol. 2017, 64, 103-110. [CrossRef] [PubMed]

5. Loureiro, V.; Malfeito-Ferreira, M. Spoilage yeasts in the wine industry. Int. J. Food Microbiol. 2003, 86, 23-50. [CrossRef]

6. Fleet, G.H. Wine yeasts for the future. FEMS Yeast Res. 2008, 8, 979-995. [CrossRef] [PubMed]

7. Jolly, N.P.; Varela, C.; Pretorius, I.S. Not your ordinary yeast: Non-Saccharomyces yeasts in wine production uncovered. FEMS Yeast Res. 2014, 14, 215-237. [CrossRef] [PubMed]

8. Padilla, B.; Gil, J.V.; Manzanares, P. Past and Future of Non-Saccharomyces Yeasts: From Spoilage Microorganisms to Biotechnological Tools for Improving Wine Aroma Complexity. Front. Microbiol. 2016, 7, 411. [CrossRef] [PubMed]

9. Peña, R.; Chávez, R.; Rodríguez, A.; Ganga, M.A. A Control Alternative for the Hidden Enemy in the Wine Cellar. Fermentation 2019, 5, 25. [CrossRef]

10. Escott, C.; Del Fresno, J.M.; Loira, I.; Morata, A.; Suárez-Lepe, J.A. Zygosaccharomyces rouxii: Control Strategies and Applications in Food and Winemaking. Fermentation 2018, 4, 69. [CrossRef]

11. Vejarano, R. Saccharomycodes ludwigii, Control and Potential Uses in Winemaking Processes. Fermentation 2018, 4, 71. [CrossRef]

12. Loira, I.; Morata, A.; Palomero, F.; González, C.; Suárez-Lepe, J.A. Schizosaccharomyces pombe: A Promising Biotechnology for Modulating Wine Composition. Fermentation 2018, 4, 70. [CrossRef]

13. Ramírez, M.; Velázquez, R. The Yeast Torulaspora delbrueckii: An Interesting But Difficult-To-Use Tool for Winemaking. Fermentation 2018, 4, 94. [CrossRef]

14. Martin, V.; Valera, M.J.; Medina, K.; Boido, E.; Carrau, F. Oenological Impact of the Hanseniaspora/Kloeckera Yeast Genus on Wines-A Review. Fermentation 2018, 4, 76. [CrossRef]

15. García, M.; Esteve-Zarzoso, B.; Cabellos, J.M.; Arroyo, T. Advances in the Study of Candida stellata. Fermentation 2018, 4, 74. [CrossRef]

16. Padilla, B.; Gil, J.V.; Manzanares, P. Challenges of the Non-Conventional Yeast Wickerhamomyces anomalus in Winemaking. Fermentation 2018, 4, 68. [CrossRef]

17. Morata, A.; Loira, I.; Tesfaye, W.; Bañuelos, M.A.; González, C.; Suárez Lepe, J.A. Lachancea thermotolerans Applications in Wine Technology. Fermentation 2018, 4, 53. [CrossRef]

18. Morata, A.; Loira, I.; Escott, C.; del Fresno, J.M.; Bañuelos, M.A.; Suárez-Lepe, J.A. Applications of Metschnikowia pulcherrima in Wine Biotechnology. Fermentation 2019, 5, 63. [CrossRef] 
19. Bozoudi, D.; Tsaltas, D. The Multiple and Versatile Roles of Aureobasidium pullulans in the Vitivinicultural Sector. Fermentation 2018, 4, 85. [CrossRef]

20. Vilela, A. Use of Nonconventional Yeasts for Modulating Wine Acidity. Fermentation 2019, 5, 27. [CrossRef]

21. Ivit, N.N.; Kemp, B. The Impact of Non-Saccharomyces Yeast on Traditional Method Sparkling Wine. Fermentation 2018, 4, 73. [CrossRef] 